BMJ Open Sport \& Exercise Medicine

\title{
Mortality of Japanese Olympic athletes: 1952-2017 cohort study
}

Taro Takeuchi (D , , Yuri Kitamura, ${ }^{1}$ Junya Sado, ${ }^{2}$ Satoshi Hattori, ${ }^{3}$ Yumiko Kanemura, ${ }^{4}$ Yoshihiko Naito, ${ }^{4}$ Kohei Nakajima, ${ }^{5,6}$ Toru Okuwaki, ${ }^{5}$ Ken Nakata, ${ }^{2}$ Takashi Kawahara, ${ }^{5,6}$ Tomotaka Sobue ${ }^{1}$

To cite: Takeuchi T, Kitamura Y, Sado J, et al. Mortality of Japanese Olympic athletes: 1952-2017 cohort study. BMJ Open Sport \& Exercise Medicine 2019;5:e000653. doi:10.1136/ bmjsem-2019-000653

- Additional material is published online only. To view please visit the journal online (http://dx.doi.org/10.1136/ bmjsem-2019-000653)

Accepted 22 0ctober 2019

Check for updates

(C) Author(s) (or their employer(s)) 2019. Re-use permitted under CC BY-NC. No commercial re-use. See rights and permissions. Published by BMJ.

${ }^{1}$ Department of Social Medicine, Osaka University, Suita, Japan ${ }^{2}$ Department of Health and Sports Sciences, Osaka University, Suita, Japan ${ }^{3}$ Department of Integrated Medicine, Osaka University, Suita, Japan

${ }^{4}$ Department of Food Science and Nutrition, Mukogawa Women's University, Nishinomiya, Japan ${ }^{5}$ Japan Institute of Sports Sciences, Kita-ku, Japan ${ }^{6}$ Japanese Olympic Committee, Tokyo, Japan

\section{Correspondence to}

Dr Yuri Kitamura;

ytkitamura@envi.med.osaka-u. ac.jp; tarogauss106072@gmail. com

\section{ABSTRACT}

Aim To evaluate mortality among Japanese Olympic athletes compared with the general population and also evaluate their mortality based on total number of Olympics participation and intensity of sports disciplines.

Methods Information on biography, vital status, date of birth, date of death and latest follow-up date on Japanese Olympians was retrieved from six online databases and compared. Standardised mortality ratio (SMR) was estimated according to observation periods and years from last participation in the Olympics. To further evaluate the association between mortality and total number of Olympics participation/intensity of sports disciplines within the study population, rate ratios (RRs) adjusted by sex, observation period and attained age group were estimated by a Poisson regression model.

Results A total of 3381 Olympians were included in the analysis. The total person years was 94076.82 . The deaths of $153(4.53 \%)$ Olympians were confirmed, and the overall SMR was 0.29 (95\% $\mathrm{Cl}, 0.25$ to 0.34$)$. SMRs categorised by years from last participation did not differ significantly. Higher mortality was observed among those who participated in the Olympics twice (RR: $1.52 ; 95 \% \mathrm{Cl}$, 1.04 to 2.23 ) and three times or more (RR: $1.87 ; 95 \% \mathrm{Cl}$, 1.08 to 3.25 ) compared with those who participated just once. Compared with combination of low static and low dynamic intensity category, higher mortality was observed in most combinations of middle-intensity or high-intensity categories.

Conclusion Japanese Olympians lived longer than the general population. More frequent participation in the Olympics and higher intensity of sports disciplines were associated with higher mortality.

\section{INTRODUCTION}

It is well known that a moderate level of sports activity plays an important role in maintaining our health. ${ }^{1-6}$ However, there is still room for debate about whether high-intensity exercises deteriorate our health. Elite athletes are exposed to high-intensity exercise for a long period of time. Although some studies reported increased mortality by specific causes of death among competitive athletes, ${ }^{7-12}$ a recent systematic review ${ }^{13}$ reported lower mortality among elite athletes. Many previous

\section{What are the new findings?}

- Japanese Olympic athletes lived longer compared with the general population, which was consistent with previous studies in other countries.

- Standardised mortality ratio (SMR) was similar according to the years from last participation, although lower SMR at the beginning of the follow-up was expected due to the cohort selection effect.

- Greater number of participation in the Olympic games and higher intensity of sports disciplines were associated with higher mortality.

How might it impact on clinical practice in the future?

Higher mortality among Olympic athletes with greater number of Olympics participation suggests the need for careful support for Olympic athletes with long careers.

studies also reported lower overall mortality among elite athletes. ${ }^{14-19}$

Olympic athletes are representative of elite athletes. Previous studies reported that Olympic athletes lived longer compared with the general population. ${ }^{20-28}$ However, evidence for their lower mortality is still insufficient because there is lack of follow-up after they retire from international competitions, and public documents on their vital statuses are also insufficient. In particular, retrospective cohort studies on Olympic athletes have never been conducted in Asian countries.

Olympic athletes are public figures, so some information on their vital status is available on online databases. This online information has not been utilised sufficiently in previous studies. In this study, we established a cohort of Japanese Olympic athletes and evaluated their mortality compared with the Japanese general population by calculating standardised mortality ratio (SMR). In addition, we evaluated the association between their mortality and total number of Olympics participation/intensity of sports disciplines. 


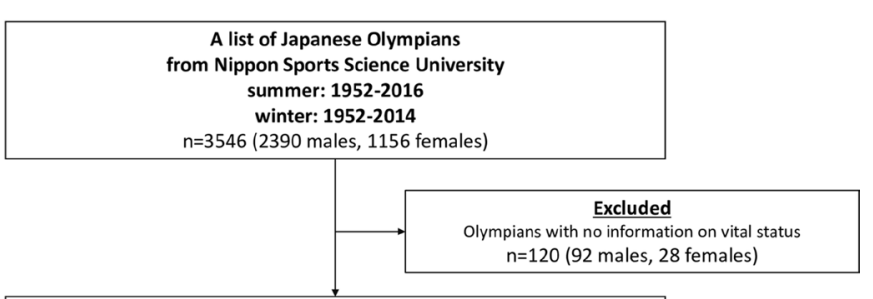

Japanese Olympians whose vital status was confirmed summer: 1952-2016 winter: 1952-2014 $\mathrm{n}=3426$ (2298 males, 1128 females $)$

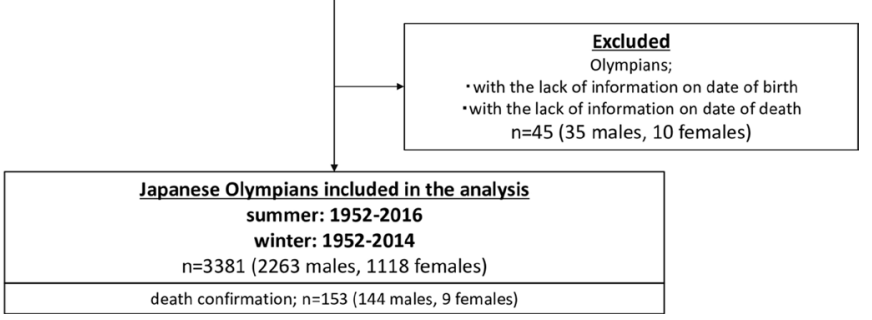

Figure 1 Flow diagram for the analysis. Among 3381

Olympians, 91 Olympians with lack of information on the sports discipline they participated in were not included in the Poisson regression (table 3 ).

\section{METHODS}

\section{Data source and processing}

The flow diagram of data processing is described in figure 1 . To select subjects for this study, we first obtained from Nippon Sports Science University a list of Japanese athletes who participated in at least one Olympic Games held after World War II. This list contained the biography of 3546 Japanese Olympic athletes (2390 men and 1156 women). We then searched for additional biographical information on these Olympians by using SR/OLYMPIC SPORTS (https://www.sports-reference. com/olympics/), which is the largest online database of Olympic athletes, and Wikipedia (https://www.wikipedia.org/). Subsequently, we retrieved information on each Olympian's vital status from five different sources of data: SR/OLYMPIC SPORTS, the list of Olympians (edited by the Japan Olympic Committee), Kikuzo II Visual (the online database of articles in the Asahi Shimbun), MAISAKU (the online database of articles in the Mainichi Shimbun), and Wikipedia. When we could not obtain information on vital status from these five sources of data, we conducted additional Google searches (https://www.google.co.jp/).

When information on an Olympian's death was obtained from at least one source of data, we assumed his or her vital status to be 'dead'. For Olympians whose day of death could not be confirmed, it was assumed that they died at the beginning of the month. For Olympians whose month and day of death could not be confirmed, it was assumed that they died on July 1 . When the date of death was inconsistent between more than two sources of data, the date from the most reliable source of data was chosen. Algorithms for selecting information are described in online supplementary contents 1 .

\section{Follow-up and study endpoints}

Follow-up started at the last participation date. For an Olympian whose vital status was 'dead', the follow-up ended at the date of death. For an Olympian whose vital status was 'alive', the follow-up ended at the earlier date of the latest follow-up date or 31 December 2017.

\section{Classification of sports disciplines}

Sports disciplines were classified based on the intensity that was required to perform the discipline during the competition. All Olympic sports in which Japanese athletes participated were classified according to the eighth Task Force on the Classification of Sports. ${ }^{21} 2930$ Intensity of sports disciplines were categorised by nine combinations of static intensity (low, middle and high) and dynamic intensity (low, middle and high). Higher intensity corresponded to higher cardiovascular demand..$^{29} 30$

\section{Statistical analysis}

$\mathrm{SMR}^{3132}$ and $95 \%$ CI were estimated to evaluate mortality among Japanese Olympic athletes compared with the general population. Methods of calculating SMR are described in online supplementary contents 2 . SMR was estimated according to observation periods (1948-1997, 1998-2007 and 2008-2017) and years from last participation in the Olympic Games $(0$ to $<10,10$ to $<20,20$ to $<30$ and 30 ). The Japanese population was selected as the reference group, and age-sex-calendar year specific mortality was used. The age grouping consisted of 5-year intervals from the ages of 0-4 up to 90-94. Calendar years consisted of 5-year intervals from 01 January 1948 to 31 December 2017. In Japan, the death rate of the general population is described in demographic statistics.

Rate ratio (RR) and 95\% CI were estimated to evaluate the association between the Olympians' mortality and total number of Olympics participation $(1,2,3$ or more)/intensity of sports disciplines in which they were involved. The RR was estimated using the Poisson regression model. The reference group was set at 1 (total number of participation), low static and low dynamic intensity (intensity of sports disciplines). In this model, sex, observation period (1948-1997, 1998-2007 and 2008-2017) and attained age group (0-29, 30-34, 35-39, 40-44, 45-49, 50-54, 55-59, 60-64, 65-69, 70-74, 75-79, $80-84,85-89$ and $90-99$ years) were adjusted.

Sensitivity analysis was performed by excluding 1324 Olympians without individual latest follow-up date, and the SMR was estimated as described above. All analyses were performed using Stata/MP V.15.0, and the statistical significance level was set at 0.05 .

\section{Patient and public involvement}

This research was conducted without patient involvement. Patients were not invited to comment on the study design and were not consulted to develop patient relevant outcomes or interpret the results. Patients were not invited to contribute to the editing of this document for readability or accuracy. 
Table 1 The distribution of year of death and year of latest follow-up

\begin{tabular}{|c|c|c|c|c|c|c|}
\hline \multirow[b]{2}{*}{ Observation period } & \multicolumn{2}{|l|}{ Death confirmation } & \multicolumn{4}{|c|}{ Latest follow-up date } \\
\hline & Number of deaths & $\%$ & With individual & $\%$ & Without individual & $\%$ \\
\hline 1960-1964 & 1 & 0.65 & 0 & 0 & 0 & 0 \\
\hline 1965-1969 & 1 & 0.65 & 0 & 0 & 0 & 0 \\
\hline 1970-1974 & 0 & 0 & 0 & 0 & 0 & 0 \\
\hline 1975-1979 & 3 & 1.96 & 0 & 0 & 0 & 0 \\
\hline $1980-1984$ & 10 & 6.54 & 0 & 0 & 0 & 0 \\
\hline 1985-1989 & 4 & 2.61 & 0 & 0 & 0 & 0 \\
\hline 1990-1994 & 10 & 6.54 & 0 & 0 & 0 & 0 \\
\hline 1995-1999 & 11 & 7.19 & 1 & 0.05 & 0 & 0 \\
\hline 2000-2004 & 37 & 24.18 & 15 & 0.79 & 0 & 0 \\
\hline 2005-2009 & 30 & 19.61 & 45 & 2.36 & 0 & 0 \\
\hline 2010-2014 & 28 & 18.3 & 149 & 7.83 & 0 & 0 \\
\hline 2015-2017 & 18 & 11.76 & 1694 & 88.97 & 1324 & 100 \\
\hline Total & 153 & 100 & 1904 & 100 & 1324 & 100 \\
\hline
\end{tabular}

\section{RESULTS}

\section{Cohort characteristics}

Through the search process, the vital status was confirmed for 3426 (2298 men and 1128 women) Olympians. The vital status for 120 (92 men and 28 women) Olympians could not be confirmed. Among the 3426 Olympians, 45 (35 men and 10 women) whose year of death/birth was unknown were excluded. Among the 45 Olympians excluded, we could not confirm the year of death for 6 ( 5 men and 1 woman), the year of birth for 38 (29 men and 9 women), and the year of death and year of birth for one male. As a result, 3381 (2263 men and 1118 women) Olympians were included in the final analysis.

Among the 3381 Olympians selected for analysis, deaths were confirmed for 153 (144 men and 9 women). The distribution of year of death is described in table 1 . In all, 19 (12.42\%) deaths were confirmed between 1960 and 1989 , while $134(87.58 \%)$ deaths were confirmed after 1990. The distribution of latest follow-up year is described in table 1. Among 3228 Olympians, latest follow-up date with individual were confirmed for 1904 (58.98\%) Olympians. For 1324 (41.02\%) Olympians whose vital status was confirmed only by SR/OLYMPIC SPORTS, we could not collect the latest follow-up date because SR/OLYMPIC SPORTS did not provide that information. We assumed that these Olympians lived until the end of follow-up (31 December 2017).

Olympic athletes were also classified according to the last Olympic game in which they participated. After World War II, Japan participated in the Olympic Games for the first time in the VI Olympic Winter Games held in 1952 in Oslo. Online supplementary table 1 describes the total number of deaths and confirmed deaths of the 3381 Japanese Olympians eligible for the analysis according to the last participated Olympic Games. 153 (4.53\%) deaths were confirmed; $144(6.36 \%)$ of these deaths were men, in contrast to only $9(0.81 \%)$ deaths among women.

\section{Cohort classification by sports discipline}

Olympians were classified according to the intensity of sports discipline in which they participated during the Olympic competition (figure 2). Static intensity estimates the extent of voluntary muscle contraction, and dynamic intensity estimates the amount of oxygen uptake. Among the 3381 Olympians included in the final analysis, 91 (63 men and 28 women) could not be classified due to lack of detailed information on the sports disciplines in which they participated. As a result, 3290 Olympians (2200 men and 1090 women) were included in the analysis using the Poisson regression model. Among these 3290 Olympians, deaths were confirmed for 150 (142 men and 8 women) individuals.

\section{Mortality analyses}

The mean $( \pm \mathrm{SD})$ of age at the end of follow-up was 53.10 $( \pm 17.52)$. Table 2 describes total person years, number of deaths, expected number of deaths and SMR with $95 \%$ CI according to the observation period and years from last participation in the Olympic Games. Total person years was 94076.82, and the overall SMR was 0.29 (95\% CI, 0.25 to 0.34$)$. The SMR was higher in $1998-2007(0.41 ; 95 \%$ CI, 0.32 to 0.53 ) compared with the other two observation periods. The SMR was similar among the four categories of years from last participation in the Olympic Games, but the highest SMR was observed between 0 and 10 years from last participation in the Olympics $(0.36 ; 95 \%$ CI, 0.19 to 0.62$)$. SMRs categorised by total number of participation in the Olympic games were also calculated (online supplementary table 2). Mortality was lower than the general population among those who participated in the Olympic games three times or more. 


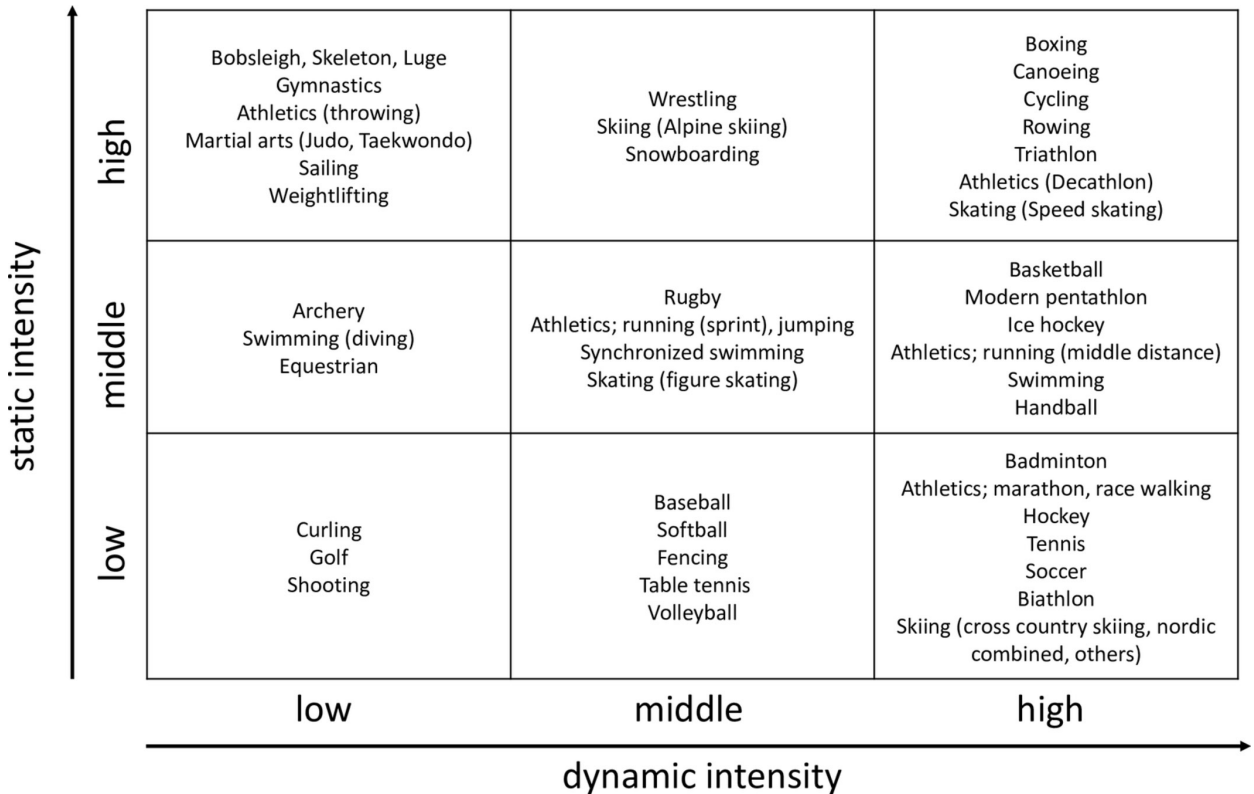

Figure 2 Classification of sports disciplines in the Olympic Games according to static intensity and dynamic intensity. The static intensity corresponds to maximal voluntary muscle contraction. The dynamic intensity corresponds to the maximal oxygen uptake. We identified the sports disciplines that 3290 Olympians participated in.

In the analysis of Olympians by total number of Olympics participation and intensity of sports disciplines (table 3), statistically significant ( $\mathrm{p}$ for trend, 0.005) higher mortality was observed among those who participated in the Olympic Games twice (RR: 1.52; 95\% CI, 1.04 to 2.23 ) and three times or more (RR: $1.87 ; 95 \%$ CI, 1.08 to 3.25$)$. Higher mortality was observed among categories of higher intensity compared with the reference category, except for middle static and low dynamic intensity category (RR: $0.74 ; 95 \%$ CI: 0.12 to 4.45$]$ ).

\section{Sensitivity analyses}

Online supplementary table 3 describes total person years, number of deaths, expected number of deaths and SMR with $95 \%$ CI from a sensitivity analysis according to the observation period. The total person years was
46617.69, and the overall SMR was 0.74 (95\% CI, 0.63 to 0.86$)$.

\section{DISCUSSION}

From this large, retrospective cohort study targeting 3546 Japanese Olympic athletes, we observed significant lower mortality among Olympians compared with the Japanese general population. The overall SMR was 0.29 (95\% CI, 0.25 to 0.34$)$. As far as we know, this is the first study that reported superior longevity among Asian Olympic athletes. The results were consistent with previous studies conducted in other non-Asian countries, but the SMR was lower than in previous studies. A retrospective cohort study $^{22}$ targeting 203 French Olympic rowers reported that the SMR for all causes of death was 0.58 (95\% CI:

Table 2 SMR with $95 \% \mathrm{Cl}$ according to the observation period and years from last participation in the Olympic Games

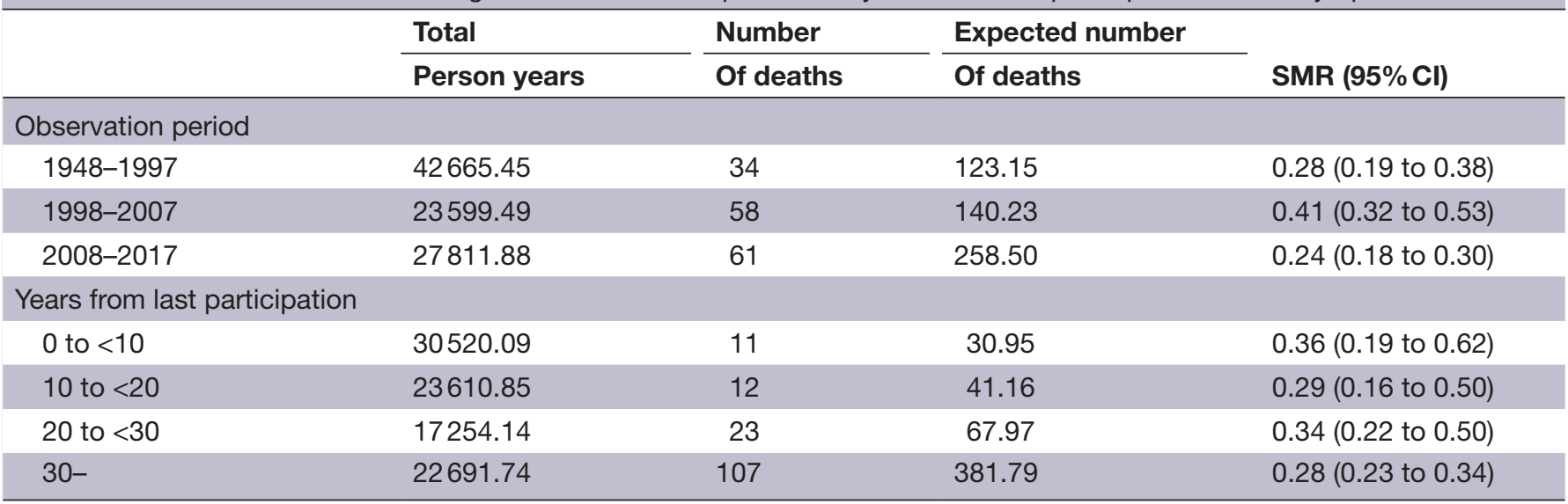

SMR, standardised mortality ratio. 
Table 3 Rate ratio and $95 \% \mathrm{Cl}$ by poisson regression

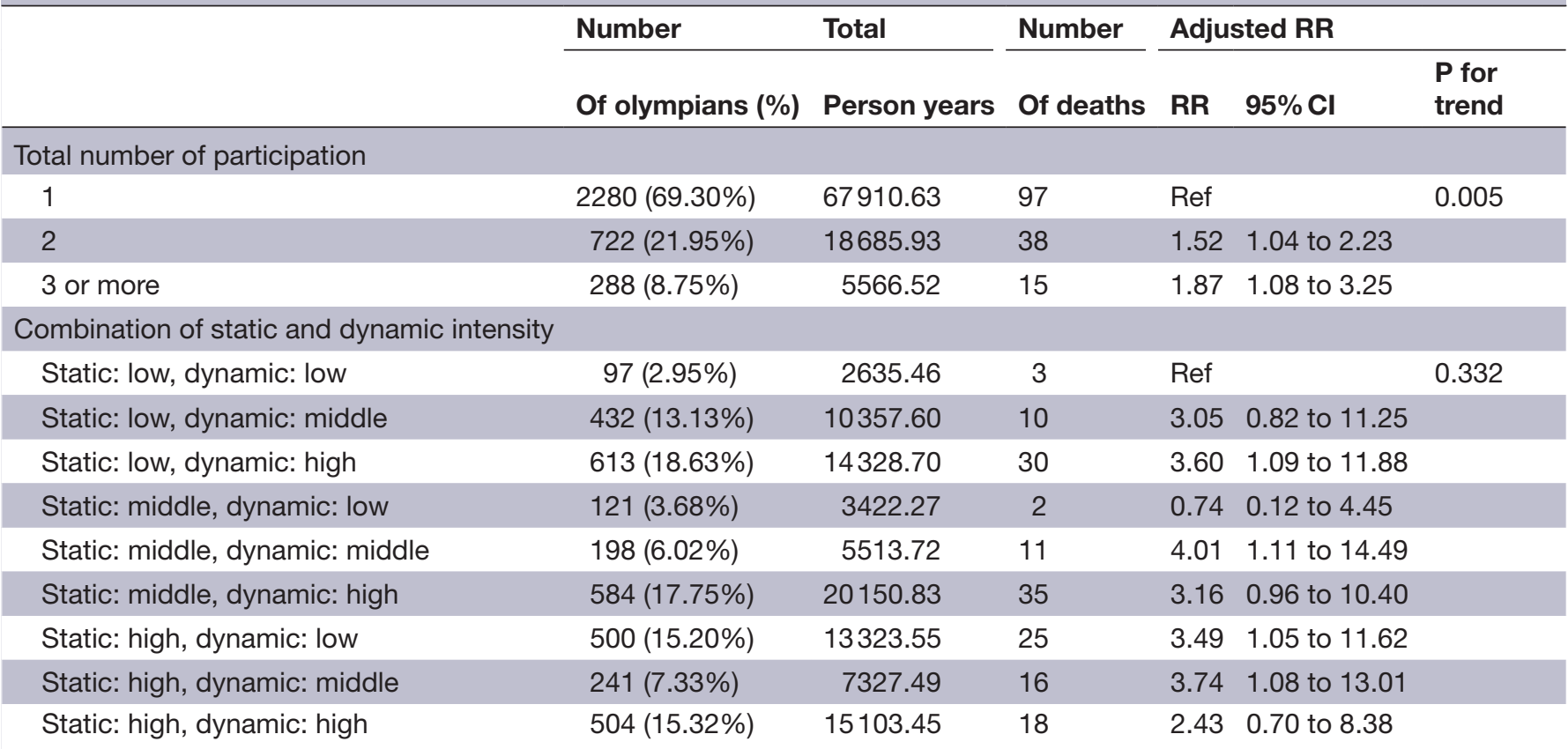

0.43 to 0.78$)$. Another retrospective cohort study ${ }^{23}$ targeting 2403 French Olympic athletes reported a SMR of 0.49 (95\% CI, 0.26 to 0.85 ) among women and 0.51 (95\% CI, 0.45 to 0.59 ) among men. A third retrospective cohort study $^{26}$ of 233 Croatian male Olympic medalists reported a SMR of 0.73 (95\% CI, 0.56 to 0.94$)$.

In the analysis by total number of participation in the Olympic Games, significantly higher mortality was observed among those who participated in the Olympics more than twice compared with those who participated only once. The underlying reason for this may be that those who participated in Olympic Games many times may have had long careers as elite athletes. To be continuously successful, they could have been exposed to exercises with high intensity for long periods, which may have led to higher mortality compared with those who participated only once. Higher mortality among Olympic athletes with greater number of Olympics participation suggests the need for careful support for Olympic athletes with long careers.

When looking at years from last participation in the Olympic Games, we expected to observe a lower SMR at the beginning of the follow-up period because of the healthy worker effect, ${ }^{33}$ which is defined as the difference in mortality due to cohort selection. ${ }^{33}$ This effect was observed in previous studies that targeted highly selected subjects. ${ }^{1534}$ In our study, we expected to observe a healthy worker effect because the cohort of Japanese Olympic athletes was assumed to be composed of mostly healthy individuals. However, the highest SMR was observed at the beginning of the follow-up period, which could be explained in part by sudden deaths or suicides among young athletes. Several previous studies ${ }^{7-11}$ have reported sudden deaths among young competitive athletes. A 21-year prospective cohort study ${ }^{7}$ of adolescents and young adults in Italy concluded that the relative risk of sudden death among athletes was 1.95 (95\% CI, 1.30 to 2.60) for men and 2.00 (95\% CI, 0.60 to 4.90$)$ for women compared with non-athletes. Another study ${ }^{12}$ demonstrated higher mortality due to suicide among former elite athletes; mortality due to suicide among those 30-50 years of age was 2-4 times higher than the general population. In our study, we could not collect accurate causes of death due to lack of information in the publicly available databases. We are planning to conduct another study that investigates causes of death among young Olympic athletes.

Higher intensity of sports disciplines was associated with mortality in most combinations of middle-intensity or high-intensity categories. A previous study ${ }^{21}$ could not provide evidence that former Olympic athletes involved in high-intensity disciplines had a higher mortality compared with other former Olympic athletes. In contrast, we conducted cohort classification by sport discipline according to the nine combinations of static and dynamic intensity of sports disciplines, and demonstrated the association between intensity of sports disciplines and mortality. We did not observe significantly higher mortality among athletes who participated in disciplines of highest static and highest dynamic intensity. This could be explained in part by their exercise habits after retiring from international competitions. Although a study reported that those capable of prolonged vigorous physical exercises lived longer compared with the general population, ${ }^{35}$ Olympic athletes involved in sports disciplines with high intensity may not necessarily continue sports activities after retirement. The habit of sports activities after retiring from athletics may have more 
influence on mortality than the static/dynamic intensity of each sports discipline. To elucidate the exercise habits among Japanese former Olympic athletes, we are planning to conduct questionnaires on their sports activities after they retired from international competition.

The overall SMR estimated in the sensitivity analysis may indicate the upper limit of SMR because we excluded Olympians whose vital status was confirmed to be 'alive' and for whom latest follow-up dates could not be confirmed. The overall SMR in the sensitivity analysis was lower than 1.0, which reinforced the idea that Japanese Olympians lived longer than the general population.

\section{Strengths and limitations}

This study had three strengths: (1) to the best of our knowledge, the number of Olympians included in this study (3381) was larger compared with previous studies; (2) we demonstrated that greater number of participation in the Olympic games was associated with higher mortality, which indicates the need to support Olympians after they retire. This is especially important after their long careers; (3) in this study, we searched information from different online databases which were open to the public. After collecting information, we compared it and chose the information from the most reliable data source using unified algorithms. We thereby assured the completeness of the data.

There were four limitations to our study results. (1) we could not find adequate information on Olympic athletes who died in the past due to the lack of information in publicly available databases. We were able to confirm the deaths of 153 Olympians, and the earliest year of death was 1964. Public databases, especially online databases of newspapers, contain information on deaths with more recent dates (after around 1990), but they do not contain information on deaths further in the past. Therefore, the observed number of deaths and the SMR could be underestimated in our study; (2) we could not compare the longevity of Olympic athletes with the general population matched for socioeconomic status; (3) we could not evaluate the effect of health habits including use of doping on Olympians' mortality; and (4) we could not adjust for cumulative training load in the multivariate analysis.

\section{Perspectives}

In this study, the results of survival analyses suggested that lifestyles of Olympic athletes after they retired from international competitions may have influenced their mortality. To investigate their lifestyles and health status after retirement from international competitions and thereby help and protect more Olympians, we are planning to conduct a questionnaire and an interview targeting the families and acquaintances of former Olympians.

We were not able to calculate SMR according to each cause of death because we could not validate each Olympian's cause of death by national death statistics. To validate causes of deaths by national death statistics, we have to confirm the vital status of each Olympian, the date of birth and the date of death. In this study, we could not investigate this type of information completely due to the lack of such information in online databases. After we are able to supplement this type of missing information by a questionnaire or an interview targeting the families and acquaintances of former Olympians, we plan to conduct another study using national death statistics.

\section{CONCLUSION}

Consistent with the results of previous research, this study demonstrated that Olympic athletes lived longer than the general population. Higher mortality was observed among those who participated in the Olympic games more frequently, but their mortality was still lower than the Japanese general population. Higher intensity of sports disciplines was associated with higher mortality.

Acknowledgements We thank Hidetoshi Akiyama and Junko Sato for their support in data collection. This study was supported by the Osaka University Medical Doctor Scientist Training Program.

Contributors TT collected the data from online databases, processed the data, conducted analyses and wrote the manuscript. SH contributed to the analyses and reviewed the manuscript from the biostatistical point of view. Other co-authors contributed to the study design, data collection and analyses, and revised the manuscript. All of the authors have approved the final manuscript.

Funding This study was supported by Grant-in-Aid for challenging Exploratory Research (17K19906) and Sports Research Innovation Project (SRIP).

Competing interests None declared.

Patient consent for publication Not required.

Provenance and peer review Not commissioned; internally peer reviewed.

Data availability statement No data are available.

Open access This is an open access article distributed in accordance with the Creative Commons Attribution Non Commercial (CC BY-NC 4.0) license, which permits others to distribute, remix, adapt, build upon this work non-commercially, and license their derivative works on different terms, provided the original work is properly cited, appropriate credit is given, any changes made indicated, and the use is non-commercial. See: http://creativecommons.org/licenses/by-nc/4.0/.

ORCID iD

Taro Takeuchi http://orcid.org/0000-0002-9900-9608

\section{REFERENCES}

1 Powell KE, Paluch AE, Blair SN. Physical activity for health: what kind? how much? how intense? on top of what? Annu Rev Public Health 2011;32:349-65.

2 Kokkinos P. Physical activity, health benefits, and mortality risk. ISRN Cardiol 2012;2012:1-14

3 Schnohr P, Marott JL, Lange P, et al. Longevity in male and female joggers: the Copenhagen City heart study. Am J Epidemiol 2013;177:683-9.

4 Hupin D, Edouard P, Gremeaux V, et al. Physical activity to reduce mortality risk. Eur Heart J 2017;38:1534-7.

5 Schnohr P, O'Keefe JH, Marott JL, et al. Dose of jogging and longterm mortality: the Copenhagen City heart study. J Am Coll Cardiol 2015;65:411-9.

6 Sherman SE, D'Agostino RB, Cobb JL, et al. Does exercise reduce mortality rates in the elderly? Experience from the Framingham heart study. Am Heart J 1994;128:965-72.

7 Corrado D, Basso C, Rizzoli G, et al. Does sports activity enhance the risk of sudden death in adolescents and young adults? $\mathrm{J} \mathrm{Am}$ Coll Cardiol 2003;42:1959-63.

8 Maron BJ, Epstein SE, Roberts WC. Causes of sudden death in competitive athletes. J Am Coll Cardiol 1986;7:204-14. 
9 Taioli E. All causes of mortality in male professional soccer players. Eur J Public Health 2007;17:600-4.

10 Angell PJ, Chester N, Sculthorpe N, et al. Performance enhancing drug abuse and cardiovascular risk in athletes: implications for the clinician. Br J Sports Med 2012;46 Suppl 1:i78-84.

11 Chandra N, Bastiaenen R, Papadakis M, et al. Sudden cardiac death in young athletes: practical challenges and diagnostic dilemmas. $J$ Am Coll Cardiol 2013;61:1027-40.

12 Lindqvist A-S, Moberg T, Ehrnborg C, et al. Increased mortality rate and suicide in Swedish former elite male athletes in power sports. Scand J Med Sci Sports 2014;24:1000-5.

13 Lemez S, Baker J. Do elite athletes live longer? A systematic review of mortality and longevity in elite athletes. Sports Med Open 2015;1.

14 Sarna S, Sahi T, Koskenvuo M, et al. Increased life expectancy of world class male athletes. Med Sci Sports Exerc 1993;25:237-44.

15 Gajewski AK, Poznańska A. Mortality of top athletes, actors and clergy in Poland: 1924-2000 follow-up study of the long term effect of physical activity. Eur J Epidemiol 2008;23:335-40.

16 Grimsmo J, Maehlum S, Moelstad P, et al. Mortality and cardiovascular morbidity among long-term endurance male cross country skiers followed for 28-30 years. Scand J Med Sci Sports 2011;21:e351-8.

17 Marijon E, Tafflet M, Antero-Jacquemin J, et al. Mortality of French participants in the tour de France (1947-2012). Eur Heart $J$ 2013;34:3145-50.

18 Zaidi A, Sharma S. Reduced mortality in former tour de France participants: the benefits from intensive exercise or a select genetic tour de force? Eur Heart J 2013;34:3106-8.

19 Kettunen JA, Kujala UM, Kaprio J, et al. All-cause and diseasespecific mortality among male, former elite athletes: an average 50-year follow-up. Br J Sports Med 2015;49:893-7.

20 Clarke PM, Walter SJ, Hayen A, et al. Survival of the fittest: retrospective cohort study of the longevity of Olympic medallists in the modern era. BMJ 2012;345:e8308.

21 Zwiers R, Zantvoord FWA, Engelaer FM, et al. Mortality in former Olympic athletes: retrospective cohort analysis. BMJ 2012;345:e7456

22 Antero-Jacquemin J, Desgorces FD, Dor F, et al. Row for your life: a century of mortality follow-up of French Olympic rowers. PLoS One 2014:9:e113362.
23 Antero-Jacquemin J, Rey G, Marc A, et al. Mortality in female and male French Olympians: a 1948-2013 cohort study. Am J Sports Med 2015;43:1505-12.

24 Antero-Jacquemin JdaS, Berthelot G, Marck A, et al. Learning from leaders: life-span trends in Olympians and supercentenarians. $J$ Gerontol A Biol Sci Med Sci 2015;70:944-9.

25 Lin Y, Gajewski A, Poznańska A. Examining mortality risk and rate of ageing among Polish Olympic athletes: a survival follow-up from 1924 to 2012. BMJ Open 2016;6:e010965.

26 Radonić V, Kozmar D, Počanić D, et al. Mortality and causes of death among Croatian male Olympic medalists. Croat Med J 2017;58:263-9.

27 Keller K. Life expectancy of Olympic wrestling champions in comparison to the general population. J Community Health 2019:44:61-7.

28 Antero-Jacquemin J, Pohar-Perme M, Rey G, et al. The heart of the matter: years-saved from cardiovascular and cancer deaths in an elite athlete cohort with over a century of follow-up. Eur J Epidemiol 2018;33:531-43.

29 Mitchell JH, Haskell W, Snell P, et al. Task force 8: classification of sports. J Am Coll Cardiol 2005:45:1364-7.

30 Levine BD, Baggish AL, Kovacs RJ, et al. Eligibility and disqualification recommendations for competitive athletes with cardiovascular abnormalities: Task force 1: classification of sports: dynamic, static, and impact: a scientific statement from the American heart association and American College of cardiology. $J$ Am Coll Cardiol 2015;66:2350-5.

31 Liddell FD. Simple exact analysis of the standardised mortality ratio. $J$ Epidemiol Community Health 1984;38:85-8.

32 Naing NN. Easy way to learn standardization : direct and indirect methods. Malays J Med Sci 2000;7:10-15.

33 McMichael AJ. Standardized mortality ratios and the "healthy worker effect": scratching beneath the surface. J Occup Environ Med 1976;18:165-8.

34 Abel EL, Kruger ML. The healthy worker effect in major league baseball revisited. Res Sports Med 2006;14:83-7.

35 van Saase JL, Noteboom WM, Vandenbroucke JP. Longevity of men capable of prolonged vigorous physical exercise: a 32 year follow up of 2259 participants in the Dutch eleven cities ice skating tour. BMJ 1990;301:1409-11. 